\title{
Common genetic variants in metabolism and detoxification pathways and the risk of papillary thyroid cancer.
}

\author{
Briseis Aschebrook-Kilfoy ${ }^{1,2}$, Gila Neta ${ }^{3}$,Alina V Brenner ${ }^{3}$, Amy Hutchinson $^{4}$, \\ Ruth M Pfeiffer ${ }^{5}$, Erich M Sturgis ${ }^{6}$, Li X ${ }^{6}{ }^{6}$, William Wheeler ${ }^{7}$, Michele M Doody ${ }^{3}$, \\ Stephen J Chanock ${ }^{4}$ and Alice J Sigurdson ${ }^{3}$
}

\footnotetext{
${ }^{1}$ Occupational and Environmental Epidemiology Branch, Division of Cancer Epidemiology and Genetics, Department of Health and Human Services, National Cancer Institute, National Institutes of Health, Bethesda, Maryland 20892, USA

${ }^{2}$ Department of Health Studies, University of Chicago, 5841 South Maryland Avenue, N101B, Chicago, Illinois 60637, USA

${ }^{3}$ Radiation Epidemiology Branch, Division of Cancer Epidemiology and Genetics, Department of Health and Human Services, National Cancer Institute, National Institutes of Health, Bethesda, Maryland 20892, USA

${ }^{4}$ Core Genotype Facility, SAIC-Frederick, Inc., Division of Cancer Epidemiology and Genetics, Department of Health and Human Services, National Cancer Institute, National Institutes of Health, Frederick, Maryland 20877, USA

${ }^{5}$ Biostatistics Branch, Division of Cancer Epidemiology and Genetics, Department of Health and Human Services, National Cancer Institute, National Institutes of Health, Bethesda, Maryland 20892, USA

${ }^{6}$ Department of Head and Neck Surgery, The University of Texas M. D. Anderson Cancer Center, Houston, Texas 77030, USA

${ }^{7}$ Information Management Services, Silver Spring, Maryland 20904, USA

(Correspondence should be addressed to B Aschebrook-Kilfoy at Department of Health Studies, University of Chicago; Email: brisa@uchicago.edu)
}

\begin{abstract}
Relationships are unclear between polymorphisms in genes involved in metabolism and detoxification of various chemicals and papillary thyroid cancer (PTC) risk as well as their potential modification by alcohol or tobacco intake. We evaluated associations between 1647 tagging single nucleotide polymorphisms (SNPs) in 132 candidate genes/regions involved in metabolism of exogenous and endogenous compounds (Phase I/II, oxidative stress, and metal binding pathways) and PTC risk in 344 PTC cases and 452 controls. For 15 selected regions and their respective SNPs, we also assessed interaction with alcohol and tobacco use. Logistic regression models were used to evaluate the main effect of SNPs $\left(P_{\text {trend }}\right)$ and interaction with alcohol/tobacco intake. Gene- and pathway-level associations and interactions ( $\left.P_{\text {gene interaction }}\right)$ were evaluated by combining $P_{\text {trend }}$ values using the adaptive rank-truncated product method. While we found associations between PTC risk and nine SNPs $\left(P_{\text {trend }} \leq 0.01\right)$ and seven genes/regions $\left(P_{\text {region }}<0.05\right)$, none remained significant after correction for the false discovery rate. We found a significant interaction between UGT2B7 and NAT1 genes and alcohol intake $\left(P_{\text {gene interaction }}=0.01\right.$ and 0.02 respectively) and between the CYP26B1 gene and tobacco intake $\left(P_{\text {gene interaction }}=0.02\right)$. Our results are suggestive of interaction between the genetic polymorphisms in several detoxification genes and alcohol or tobacco intake on risk of PTC. Larger studies with improved exposure assessment should address potential modification of PTC risk by alcohol and tobacco intake to confirm or refute our findings.
\end{abstract}

Endocrine-Related Cancer (2012) 19 333-344

\section{Introduction}

Cigarette smoking and alcohol drinking have been associated with decreased risk of thyroid cancer (Rossing et al. 2000, Mack et al. 2003, Guignard et al. 2007, Meinhold et al. 2009, 2010). These observations lend support to environmental compounds or their metabolites playing a role in the etiology of thyroid cancer, of which the primary histological type is papillary thyroid cancer (PTC), accounting for $80 \%$ of the thyroid cancer diagnoses in the USA (Howlader et al. 2011). Unknown is the effect of genetic variation in genes whose protein products are involved in metabolism or detoxification of these compounds and whether this variation modifies the 
exogenous compounds-related risk of PTC. Only two genes (FOXE1 and NKX2-1) have been identified in a genome-wide association study (GWAS) of sporadic thyroid cancer (Gudmundsson et al. 2009) with corroborating evidence for FOXE1 in another GWAS of radiation-related thyroid cancer following the Chernobyl accident (Takahashi et al. 2010). FOXE1 corresponds to thyroid transcription factor 2 (TTF2) and NKX2-1 to TTF1 both of which are involved in regulating thyroid hormone synthesis and embryonic development of the thyroid gland (De Felice \& Di Lauro 2004). Polymorphic variation in genes associated with low circulating TSH levels and increased thyroid cancer risk supports the role of thyroid hormones in relation to risk of PTC (Gudmundsson et al. 2012). Using a candidate gene approach, genes involved in detoxification have been associated with thyroid cancer, including CYP1A1 (Siraj et al. 2008), CYP2D6 (Lemos et al. 2007), GSTM1 (Lemos et al. 2008), GSTT1 (Lemos et al. 2008, Siraj et al. 2008), and NAT2 (Hernández et al. 2008, Lemos et al. 2008, Guilhen et al. 2009). Thus, there is some evidence of associations for thyroid cancer with polymorphisms in genes related to thyroid hormone metabolism and detoxification enzymes, but the prior studies were limited by a small number of cases, and most did not examine gene-environment interactions (Landa \& Robledo 2011).

To identify promising susceptibility regions associated with risk of PTC among genes whose enzyme functions act to conjugate a variety of hormones and chemicals, we adopted a candidate gene approach and used a genotyping platform developed for the purpose of analyzing the risk of several rare cancers. Here, we evaluated the main effects of 1647 single nucleotide polymorphisms (SNPs) in 132 candidate genes/regions involved in metabolism of exogenous and endogenous compounds as well as the interaction of 15 a priori selected detoxifying genes and their respective SNPs with alcohol and tobacco use. The aim of the investigation of these genes in light of exposure to alcohol or tobacco was to obtain additional insight into the etiology of PTC.

\section{Materials and methods}

\section{Study population}

This study was nested within a National Cancer Institute (NCI)-sponsored cohort study of U.S. Radiologic Technologists (USRT) and additionally included consecutively recruited PTC cases from the University of Texas M.D. Anderson Cancer Center
(UTMDACC). Both studies were reviewed and approved by their respective Institutional Review Boards and all subjects provided informed consent.

Details of the USRT cohort study design (Sigurdson et al. 2003) and selection of the USRT cases and controls for previous candidate SNP analyses of PTC (Lönn et al. 2007) were published previously. Briefly, the USRT study was initiated in 1984 and included 146022 radiologic technologists (73\% female) nationwide who were certified for at least 2 years by the American Registry of Radiologic Technologists between 1926 and 1982. Three questionnaires were administered (1983-1989, 1994-1998, and 2003-2005) to collect information on health outcomes (including reports of thyroid cancer), demographic characteristics, medical history, work practices, and other environmental risk factors. Participant response to questionnaires has consistently been $\sim 70 \%$. Thyroid cancer cases reported on any of the three questionnaires were recruited for blood collection. In 2005 there were 415 living thyroid cancer cases eligible for recruitment and, of these, 232 donated blood for analysis (55.9\%). The 491 controls used in this effort were the same as the controls used for our previous thyroid cancer study (Lönn et al. 2007). Also, included in the case group were 243 histologically confirmed thyroid cancer cases from the UTMDACC who presented for care between 1999 and 2005 at the Head and Neck Surgery Clinic and underwent subsequent surgery (Ho et al. 2009). Cases from the two studies were comparable with respect to average age at diagnosis, tumor size, smoking status, and alcohol intake.

\section{Data collection and harmonization}

Data concerning demographics, health history, family history of cancer, and other risk factors were collected by self-administered mailed questionnaires or telephone interview in the USRT study and by a selfadministered questionnaire at the time of blood collection in the UTMDACC study. Variables defined similarly in both studies were race and histological type of thyroid cancer. Other analysis variables were harmonized to be comparable across the two studies (cigarette smoking, alcohol consumption, prior exposure to therapeutic radiation, and family history of any cancer or specifically of thyroid cancer). Controls were frequency matched to cases on year of birth $( \pm 2$ years). A control for a specific case was randomly selected from strata defined by gender and year of birth. If no control could be found for a specific case, then matching on gender and year of birth was 
relaxed (in that order). To enable time-appropriate partitioning of specific exposures (such as cigarette smoking), we assigned a referent age to each control that corresponded to the matched case's age at diagnosis. The algorithm was repeated until referent age was assigned to every control. All exposures in controls were truncated at the assigned referent age.

Tobacco use was categorized as ever or never smoked more than 100 cigarettes (throughout lifetime). Alcohol use was categorized as ever or never consumed at least one drink per week. These variables were explored as potential covariates and also as factors that could modify the relationship between polymorphisms in specific genes and the risk of thyroid cancer.

\section{Laboratory methods}

\section{DNA extraction}

In the USRT study, venipuncture whole blood samples were shipped with a temperature stabilizing pack overnight to the processing laboratory in Frederick, MD. At UTMDACC, venipuncture whole blood samples were collected and processed in the clinic. Both studies extracted DNA from peripheral blood leukocytes using Qiagen Mini kits (Qiagen, Inc.) according to the manufacturer's instructions.

\section{Genotyping}

This study is based on a subset of 1647 tagging SNPs in 132 genes/regions involved in pathways related to detoxification of xenobiotic substances and metabolism of hormones from among 27904 SNPs genotyped for studies of thyroid and other cancers. Genotyping of all 27904 SNPs including tagging SNPs in 1316 candidate genes and their surrounding regions (within $20 \mathrm{~kb} \mathrm{5}^{\prime}$ of the start of transcription at the first exon and $10 \mathrm{~kb} 3^{\prime}$ of the last exon) and intergenic SNPs for both studies was performed at the NCI Core Genotyping Facility (Advanced Technology Center, Gaithersburg, MD, USA; http://cgf.nci.nih. gov/) using the custom-designed iSelect Infinium assay (Illumina, www.illumna.com). Tagging SNPs were selected for target gene regions from the common SNPs (minor allele frequency, MAF $>5 \%$ ) genotyped by the HapMap Project (Data Release 20/Phase II, NCBI Build 36.1, assembly dbSNPb126) in the Caucasian population (CEU) using TagZilla, which is part of the GLU software package (http://code.google. com/p/glu-genetics/) that was based on the pairwise binning method of Carlson et al. (2004) with a threshold $r^{2}>0.8$. Selection of gene regions of a priori interest was performed before genotyping.

\section{Quality control}

Out of 27904 SNPs included in the genotyping platform, 722 failed genotyping (no amplification or clustering) and 208 had monoallelic calls and were excluded from analysis. In addition, SNPs with $<90 \%$ completion $(n=740)$ or $<95 \%$ concordance $(n=656)$ among the 48 randomly inserted quality control replicates that ranged in size from six to 12 samples per individual were also excluded. We further excluded 740 SNPs that failed the test for Hardy-Weinberg equilibrium $(P<0.00001)$. Of the 947 study participants with DNA specimens $(n=232$ USRT cases, $n=223$ UTMDACC cases, $n=492$ USRT controls), we excluded subjects if their samples were not assayed $(n=4)$, failed genotyping $(n=18)$, or had $<90 \%$ completion $(n=15)$.

\section{Final set of tagging SNPS, pathways, and analytic} population

Following quality control-related exclusions, we excluded an additional 1607 intergenic SNPs implicated in the etiology of cancers other than thyroid and selected by other iSelect investigators plus 5706 tag SNPs with the MAF $<10 \%$ or the lowest achievable significance level computed from the marginal totals $>10^{-30}$ (Tarone 1990). After all exclusions, there were 17525 tag SNPs in 1129 genes/regions available for analysis of which 1647 SNPs in the 132 genes/ regions are involved in pathways related to the detoxification of xenobiotic substances and the metabolism of thyroid hormones and are the subject of current analysis. The candidate gene regions were subdivided into four a priori defined pathways (Phase I metabolism, Phase II metabolism, oxidative stress, and metal binding) based on evidence of biological and/or functional relatedness of the genes obtained from various publically available databases (GeneCards, in http://www-bimas.cit.nih.gov/cards//2009). When assigning gene regions with a broad range of known functions, we allowed for allocation to multiple pathways. A complete list of all candidate gene regions and their pathway allocation is available in Supplementary Table 1, see section on supplementary data given at the end of this article.

To minimize potential for population stratification and phenotypic heterogeneity of thyroid cancer cases, we also excluded individuals with non-European ancestry $(n=97)$ and cases with follicular thyroid cancer $(n=17)$, leaving 344 PTC cancer cases $(n=202$ USRT and $n=142$ UTMDACC) and 452 controls of European ancestry with validated genotyping results in the analysis. Allele frequencies for PTC cases of 
European ancestry were largely similar between the USRT and the UTMDACC study sites and between males and females, so these groups were combined for genetic analyses.

\section{Statistical analysis}

\section{SNP-based analyses}

Logistic regression models were used to estimate odds ratios (OR) and to compute $95 \%$ confidence intervals (CI) for the association of PTC risk with each SNP genotype, coded as $0,1,2$, with 0 denoting the homozygous common allele as the referent category. We calculated the linear $P_{\text {trend }}$ for SNP genotype as an ordinal variable in unadjusted models and models adjusted for gender, age in categories $(<35,35-44$, $45-54,55+)$, and year of birth $(<1940,1940-1949$, $1950+)$ as an ordinal variable. The results of adjusted and unadjusted models were essentially similar and we chose to present the results from adjusted models throughout the article. We corrected for multiple comparisons by controlling the false discovery rate (FDR; Benjamini \& Hochberg 1995).

\section{Gene/region- and pathway-based analyses}

We combined SNP-specific $P$ values of linear trend within the same gene region $\left(P_{\text {region }}\right)$ using an adaptive rank-truncated product (ARTP) method (Yu et al. 2009). Next, we also combined gene region-level $P$ values into the $P$ values associated with the four pathways $\left(P_{\text {pathway }}\right)$. We finally evaluated the significance of our overall group of 132 genes combining all gene/region-level-based $P$ values into one $\left(P_{\text {overall }}\right)$.

\section{Interaction with alcohol and tobacco intake analyses}

The genes/regions of interest and their respective SNPs included in the interaction analyses were selected among the top genes that emerged in the analysis of main effects and genes with epidemiological evidence of interaction with alcohol or tobacco intake in other studies of cancer risk. The 15 final regions selected for interaction analyses were GSTP1, GSTT2, DHRS9, FMO3, GSTT1, NAT1, UGT2B7, CYP8B1, MTF2, GSTM4/GSTM2/GSTM1/GSTM5/GSTM3, CYP2E1, NQO1, NAT2, SOD1, and CYP26B1. In the analysis of interaction between genotype and alcohol or tobacco use, the $P$ value of multiplicative interaction $\left(P_{\text {SNP-interaction }}\right)$ was calculated with the SNP genotype coded as $0,1,2$ and alcohol or tobacco use coded as 0,1 (never vs ever). The $P_{\text {SNP-interaction was determined }}$ based on the likelihood ratio test comparing logistic models with and without the interaction term. The interaction at the gene/region level was determined by combining SNP-specific interaction $P$ values within the same gene region using the ARTP method (Yu et al. 2009) which accounts for the linkage disequilibrium (LD) structure among SNPs via a permutation procedure.

All analyses were conducted using SAS version 9.1 (SAS Institute, Cary, NC, USA).

\section{Results}

Characteristics of the study population are presented in Table 1. A greater proportion of controls consisted of females (93.6\%) compared to cases $(79.7 \%$ female). This is largely because controls were originally selected from the predominately female USRT cohort to match the USRT cases and later were employed for the UTMDACC cases. More controls than cases were current smokers (25.2 vs $14.0 \%$ respectively) and slightly more controls than cases were drinkers (49.3 vs $46.1 \%$ respectively). The OR for ever vs never smoking was 0.78 (95\% CI: 0.581.06) and the OR for ever vs never drinking was 0.79 (95\% CI: 0.59-1.08) (data not shown). More controls than cases reported a family history of cancer (61.4 vs $47.7 \%$ respectively); whereas more cases than controls reported a family history of thyroid cancer (4.4 vs $1.3 \%$ respectively). The mean body mass index was higher among cases $\left(26.1 \mathrm{~kg} / \mathrm{m}^{2}\right)$ than controls $\left(24.4 \mathrm{~kg} / \mathrm{m}^{2}\right)$.

\section{SNP-based associations}

We found associations between PTC risk $\left(P_{\text {trend }} \leq 0.01\right)$ and nine SNPs distributed across seven genes/regions (Table 2; a complete list of all $P$ trend values is available in Supplemental Table 2). After correction for multiple comparisons, none of the associations remained significant.

\section{Gene/region-based associations}

Seven of the combined genes/regions were associated with PTC risk at the $P_{\text {region }}<0.05$ level. These included SOD1 $\left(P_{\text {region }}=0.003\right), C Y P 8 B 1 \quad\left(P_{\text {region }}=0.003\right)$, UGT2B7 $\left(P_{\text {region }}=0.006\right), M T F 2 \quad\left(P_{\text {region }}=0.009\right)$, GSTT1 $\left(P_{\text {region }}=0.025\right), \operatorname{DHRS} 9\left(P_{\text {region }}=0.025\right)$, and FMO3 $\left(P_{\text {region }}=0.032\right)$. A complete list of all $P$ region values is available in Supplemental Table 3.

\section{Pathway-based associations}

We found that the Phase I $\left(P_{\text {pathway }}=0.19\right)$, Phase II $\left(P_{\text {pathway }}=0.29\right)$, oxidative stress $\left(P_{\text {pathway }}=0.17\right)$, and metal binding $\left(P_{\text {pathway }}=0.26\right)$ pathways were not 
significantly associated with PTC risk, neither was the detoxification pathway as a whole $\left(P_{\text {overall }}=0.13\right)$ (Supplemental Table 1).

Table 1 Characteristics at baseline or time of blood collection for thyroid cancer cases and controls derived from the US. Radiologic Technologists Study and the UTMDACC Head and Neck Clinic

\begin{tabular}{|c|c|c|}
\hline & $\begin{array}{l}\text { Cases } \\
(n(\%))\end{array}$ & $\begin{array}{l}\text { Controls } \\
(n(\%))\end{array}$ \\
\hline Total & 344 & 452 \\
\hline \multicolumn{3}{|l|}{ Study } \\
\hline U.S. Radiologic Technologists & $202(58.7 \%)$ & $452(100.0 \%)$ \\
\hline UTMDACC & $142(41.3 \%)$ & 0 \\
\hline \multicolumn{3}{|l|}{ Gender } \\
\hline Female & $274(79.7 \%)$ & $423(93.6 \%)$ \\
\hline Male & $70(20.3 \%)$ & $29(6.4 \%)$ \\
\hline \multicolumn{3}{|l|}{ Blood collection year } \\
\hline 1998-2000 & $57(16.6 \%)$ & 0 \\
\hline $2001-2004$ & $165(48.0 \%)$ & $452(100.0 \%)$ \\
\hline 2005-2007 & $122(35.5 \%)$ & 0 \\
\hline \multicolumn{3}{|l|}{$\begin{array}{l}\text { Age at diagnosis }{ }^{a} \text { (cases) } \\
\text { and index age (controls) }\end{array}$} \\
\hline$<26$ & $27(7.8 \%)$ & $30(6.6 \%)$ \\
\hline $26-35$ & $73(21.2 \%)$ & $103(22.7 \%)$ \\
\hline $36-45$ & $113(32.8 \%)$ & $159(35.2 \%)$ \\
\hline $46-55$ & $77(22.4 \%)$ & $105(23.2 \%)$ \\
\hline $56-65$ & $43(12.5 \%)$ & $49(10.8 \%)$ \\
\hline$>65$ & $12(3.5 \%)$ & $6(1.3 \%)$ \\
\hline \multicolumn{3}{|l|}{ Smoking ${ }^{b}$} \\
\hline Never & $208(60.4 \%)$ & $234(52.2 \%)$ \\
\hline Former & $87(25.2 \%)$ & $101(22.5 \%)$ \\
\hline Current & $48(14.0 \%)$ & $113(25.2 \%)$ \\
\hline \multicolumn{3}{|l|}{ Alcohol $^{\text {b }}$} \\
\hline Never & $179(52.2 \%)$ & $213(47.5 \%)$ \\
\hline Ever & $158(46.1 \%)$ & $221(49.3 \%)$ \\
\hline Unknown & $7(2.0 \%)$ & $18(4.0 \%)$ \\
\hline \multicolumn{3}{|c|}{$\begin{array}{l}\text { Number of first-degree relatives } \\
\text { with cancer }\end{array}$} \\
\hline 0 & $170(49.4 \%)$ & $171(37.8 \%)$ \\
\hline 1 & $107(31.1 \%)$ & $180(39.8 \%)$ \\
\hline 2 & $39(11.3 \%)$ & $64(14.2 \%)$ \\
\hline 3 or more & $18(5.2 \%)$ & $33(7.3 \%)$ \\
\hline Unknown & $10(2.9 \%)$ & $4(0.8 \%)$ \\
\hline \multicolumn{3}{|c|}{$\begin{array}{l}\text { Number of first-degree relatives } \\
\text { with thyroid cancer }\end{array}$} \\
\hline No & 319 (92.7\%) & $442(97.8 \%)$ \\
\hline Yes & $15(4.4 \%)$ & $6(1.3 \%)$ \\
\hline Unknown & $10(2.9 \%)$ & 0 \\
\hline \multirow[t]{2}{*}{ Adopted } & 0 & $4(0.8 \%)$ \\
\hline & Mean (S.D.) & Mean (S.D.) \\
\hline Body mass index $\left(\mathrm{kg} / \mathrm{m}^{2}\right)$ & $26.1(6.0)$ & $24.4(4.7)$ \\
\hline
\end{tabular}

Only cases from the UTMDACC Head and Neck Clinic were available for study.

${ }^{a}$ Index age for controls was assigned based on a diagnosis age for cases as defined in the text. Index age was used to assign exposures to controls as was done for cases before their diagnosis age.

${ }^{\mathrm{b}} \mathrm{As}$ of diagnosis age in cases and index age in controls.

\section{Interaction with alcohol and tobacco use}

Among 15 genes/regions included in the interaction analyses, we identified significant interactions between $U G T 2 B 7$ and NAT1 and alcohol use $\left(P_{\text {gene-interaction }}=0.01\right.$ and 0.02 respectively $)$. At the individual SNP level, the observed interaction with the $U G T 2 B 7$ region was primarily due to significant interaction between rs3924194 and alcohol use (Table 3). In never-drinkers, the risk of PTC with rs3924194 was significantly decreased whereas in ever-drinkers the association with rs3924194 was close to null. For the NAT1 region, two SNPs (rs11777998 and rs9650592) had evidence of significant interaction with alcohol intake (Table 3). In both instances, the trends with genotypes in never-drinkers tended to go in the opposite direction compared to ever-drinkers (i.e. decreased in never-drinkers, increased in ever-drinkers).

We also found significant interaction between polymorphisms in $C Y P 26 B 1$ and cigarette smoking $\left(P_{\text {gene-interaction }}=0.02\right)$ which was attributed to interaction with three SNPs (rs975612, rs11681809, and rs194243; Table 3). Two of these (rs975612 and rs194243) were significantly associated with risk of PTC among nonsmokers and had opposing nonsignificant trends in smokers.

\section{Discussion}

Our findings provide support for the hypothesis that polymorphisms in detoxification enzymes jointly with smoking or alcohol intake might be related to risk of PTC. While we found that none of our SNP or gene region level associations withstood FDR correction, we found evidence of a significant interaction between $U G T 2 B 7$ and NAT1 genes and alcohol intake and between the $C Y P 26 B 1$ gene and cigarette smoking.

Case-control studies from throughout the world have almost uniformly found that cigarette smoking is associated with a decreased risk for thyroid carcinoma. This inverse relationship was most pronounced for comparison of current smokers with never smokers $(\mathrm{OR}=0.6 ; 95 \%$ CI 0.6-0.7) (Mack et al. 2003). Alcohol consumption has also been associated with a decreased risk of thyroid carcinoma in several studies; however, it remains unclear if the effect of alcohol is independent of smoking as both are often correlated (Mack et al. 2003). Consistent with existing evidence, we found in the present study that smoking was associated with significantly decreased risk and alcohol intake was associated with nonsignificantly decreased risk of PTC. The uniformity in magnitude and direction of the estimates supports the physiologic relevance of 
Table 2 Odd ratios (and 95\% Cl) for the tag SNPs associated with papillary thyroid cancer risk at $P_{\text {trends }}<0.01$

\begin{tabular}{|c|c|c|c|c|c|c|}
\hline Target gene & SNP & Genotype & Controls & Cases & OR & $95 \% \mathrm{Cl}$ \\
\hline SOD1 & rs1041740 & $\mathrm{CC}$ & 235 & 143 & 1.00 & Ref \\
\hline \multirow[t]{3}{*}{ Oxidative stress } & & CT & 170 & 153 & 1.46 & $1.06-2.01$ \\
\hline & & $\mathrm{TT}$ & 38 & 43 & 2.28 & $1.35-3.84$ \\
\hline & & & & & $P_{\text {trend }}$ & 0.001 \\
\hline CYP8B1 & rs6788947 & AA & 127 & 74 & 1.00 & Ref \\
\hline \multirow[t]{3}{*}{ Phase I metabolism } & & AT & 229 & 165 & 1.42 & $0.97-2.06$ \\
\hline & & TT & 96 & 105 & 2.09 & $1.37-3.20$ \\
\hline & & & & & $P_{\text {trend }}$ & 0.001 \\
\hline MTF2 & rs549938 & AA & 226 & 209 & 1.00 & Ref \\
\hline \multirow[t]{3}{*}{ Metal binding } & & $A G$ & 193 & 120 & 0.68 & $0.50-0.93$ \\
\hline & & GG & 30 & 12 & 0.39 & $0.19-0.80$ \\
\hline & & & & & $P_{\text {trend }}$ & 0.001 \\
\hline UGT2B7 & rs3924194 & $\mathrm{CC}$ & 321 & 270 & 1.00 & Ref \\
\hline \multirow[t]{3}{*}{ Phase II metabolism } & & CG & 107 & 67 & 0.65 & $0.45-0.95$ \\
\hline & & GG & 19 & 5 & 0.28 & $0.10-0.78$ \\
\hline & & & & & $P_{\text {trend }}$ & 0.001 \\
\hline CYP8B1 & rs11715464 & AA & 177 & 107 & 1.00 & Ref \\
\hline \multirow[t]{3}{*}{ Phase I metabalism } & & $A G$ & 213 & 169 & 1.55 & $1.11-1.97$ \\
\hline & & GG & 62 & 67 & 1.92 & $1.23-3.04$ \\
\hline & & & & & $P_{\text {trend }}$ & 0.002 \\
\hline SOD1 & rs12626475 & AA & 219 & 138 & 1.00 & Ref \\
\hline \multirow[t]{3}{*}{ Oxidative stress } & & $A G$ & 188 & 157 & 1.29 & $0.94-1.77$ \\
\hline & & GG & 45 & 49 & 2.08 & $1.28-3.41$ \\
\hline & & & & & $P_{\text {trend }}$ & 0.004 \\
\hline DHRS9 & rs16856430 & $A A$ & 283 & 246 & 1.00 & Ref \\
\hline \multirow[t]{3}{*}{ Oxidative stress } & & $A G$ & 148 & 87 & 0.63 & $0.45-0.88$ \\
\hline & & GG & 21 & 11 & 0.55 & $0.25-1.21$ \\
\hline & & & & & $P_{\text {trend }}$ & 0.005 \\
\hline FMO3 & rs10911641 & AA & 261 & 223 & 1.00 & Ref \\
\hline \multirow[t]{3}{*}{ Phase I metabolism } & & $A G$ & 169 & 107 & 0.70 & $0.51-0.97$ \\
\hline & & $\mathrm{GG}$ & 22 & 13 & 0.46 & $0.22-0.98$ \\
\hline & & & & & $P_{\text {trend }}$ & 0.006 \\
\hline CYP8B1 & rs7614670 & $\mathrm{AA}$ & 195 & 180 & 1.00 & Ref \\
\hline \multirow[t]{3}{*}{ Phase I metabolism } & & $A G$ & 201 & 131 & 0.70 & $0.51-0.96$ \\
\hline & & GG & 54 & 31 & 0.55 & $0.33-0.93$ \\
\hline & & & & & $P_{\text {trend }}$ & 0.006 \\
\hline
\end{tabular}

SNP-based linear $P_{\text {trend }}$ calculated based on the three-level genotype $(0,1$, and 2$)$ in logistic regression models adjusted for gender, attained age, and year of birth.

the associations. Both smoking and alcohol use have been shown to increase thyroid hormone metabolism and decrease serum thyroid hormone levels in animals and humans (Barter \& Klaassen 1994, Liu et al. 1995, Hood et al. 1999, Klaassen \& Hood 2001) with a resultant increase in TSH.

Less consistent data are available with respect to genetic polymorphisms in genes involved in metabolism and detoxification of various compounds and risk of PTC. In previous reports on polymorphisms in Phase I enzymes, an increased risk of PTC was observed for CYP1A1 (OR $=1.91 ; 95 \%$ CI: $\left.1.36-2.70, P_{\text {trend }}<0.001\right)$ (Siraj et al. 2008) and CYP2D6 genes (Lemos et al. 2007); and an increased risk of PTC was also observed for polymorphisms from Phase II enzymes including GSTT1 (OR =3.48; 95\% CI: 2.48-4.88, $\left.P_{\text {trend }}<0.001\right)$
(Gudmundsson et al. 2012), whereas a decreased risk was observed for GSTM1 (OR $=0.72$; 95\% CI: 0.52-0.99, $\left.P_{\text {trend }}<0.001\right)$ in the study by Siraj et al. (2008) as well as for both $G S T M 1$ and GSTT1 $(\mathrm{OR}=0.83 ; 95 \% \mathrm{CI}$ : $0.56-1.21 ; P=0.328$; and $\mathrm{OR}=0.66$; $95 \%$ CI: $0.39-1.12$; $P=0.123$ respectively) in the study by Lemos et al. (2007). We found several associations with Phase I (CYP8B1, FMO3) and Phase II (UGT2B7, GSTT1) genes for PTC risk, although none of these remained significant after FDR correction. We also expected to see an association with the $\mathrm{DIOl}$ gene given its role in the regulation of the bioavailability of thyroid hormones and previous reported associations for thyroid cancer with SNPs in genes regulating metabolism of thyroid hormones (Panicker et al. 2008, Gudmundsson et al. 2009, 2012). However, we observed only a borderline 


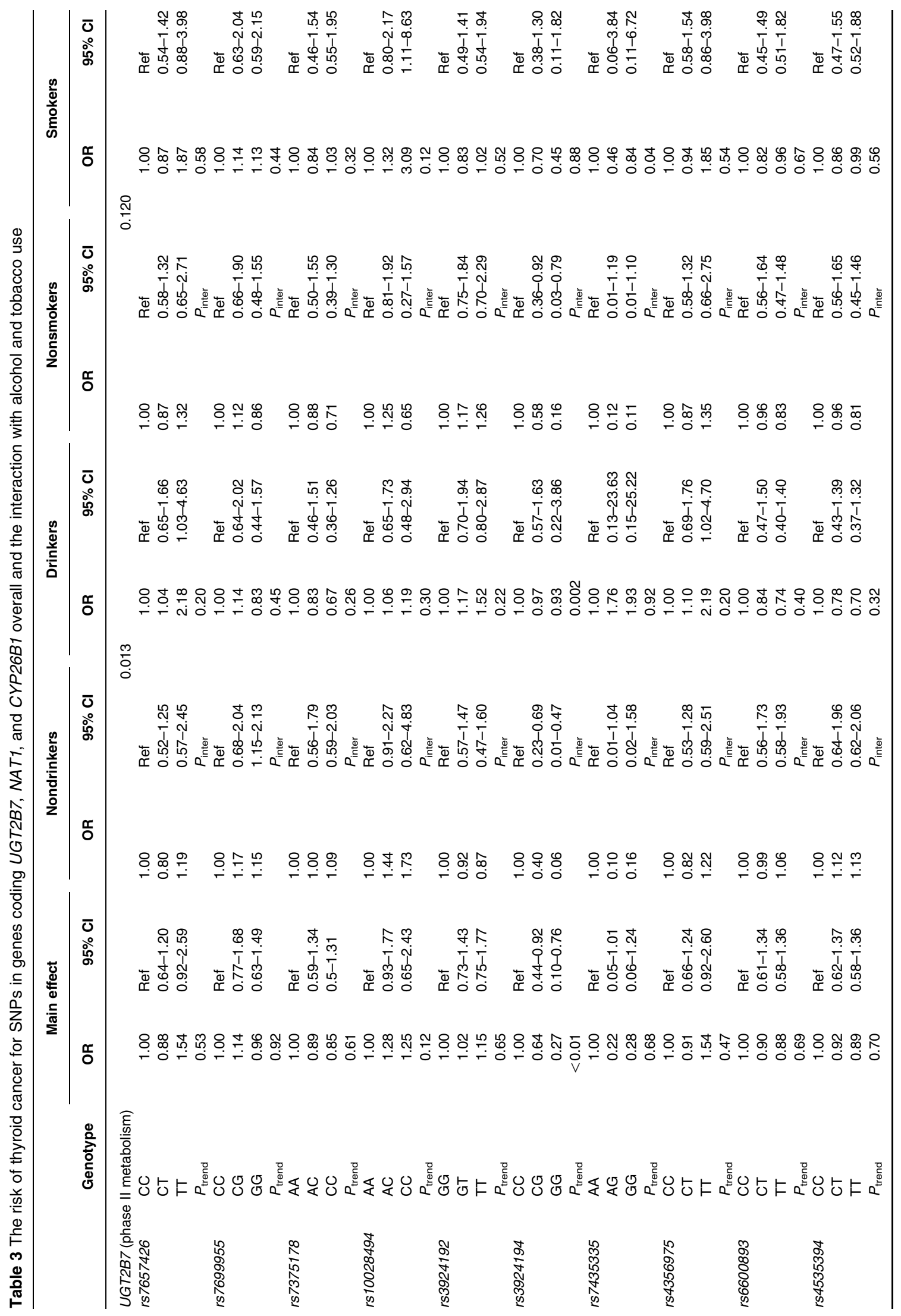




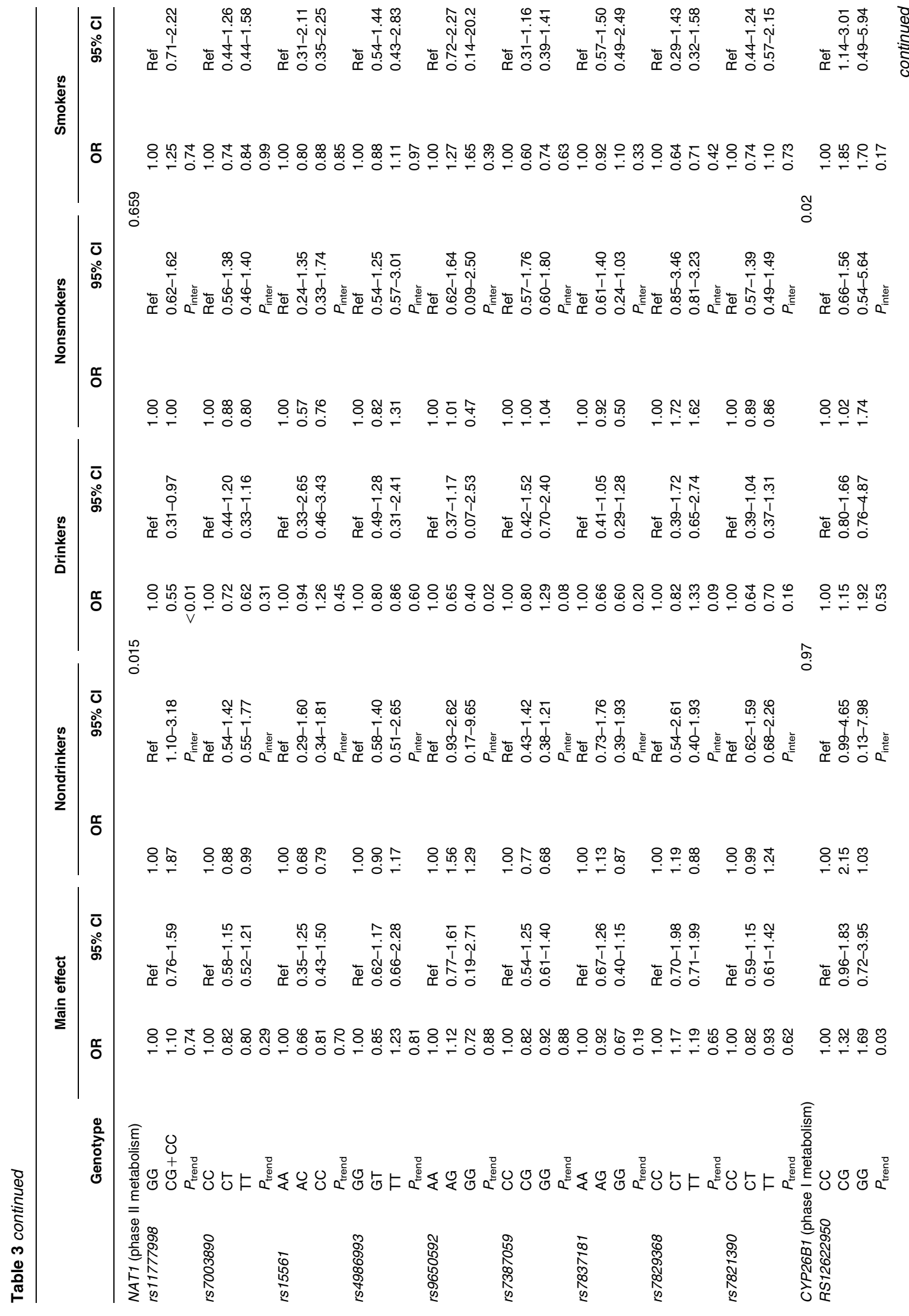




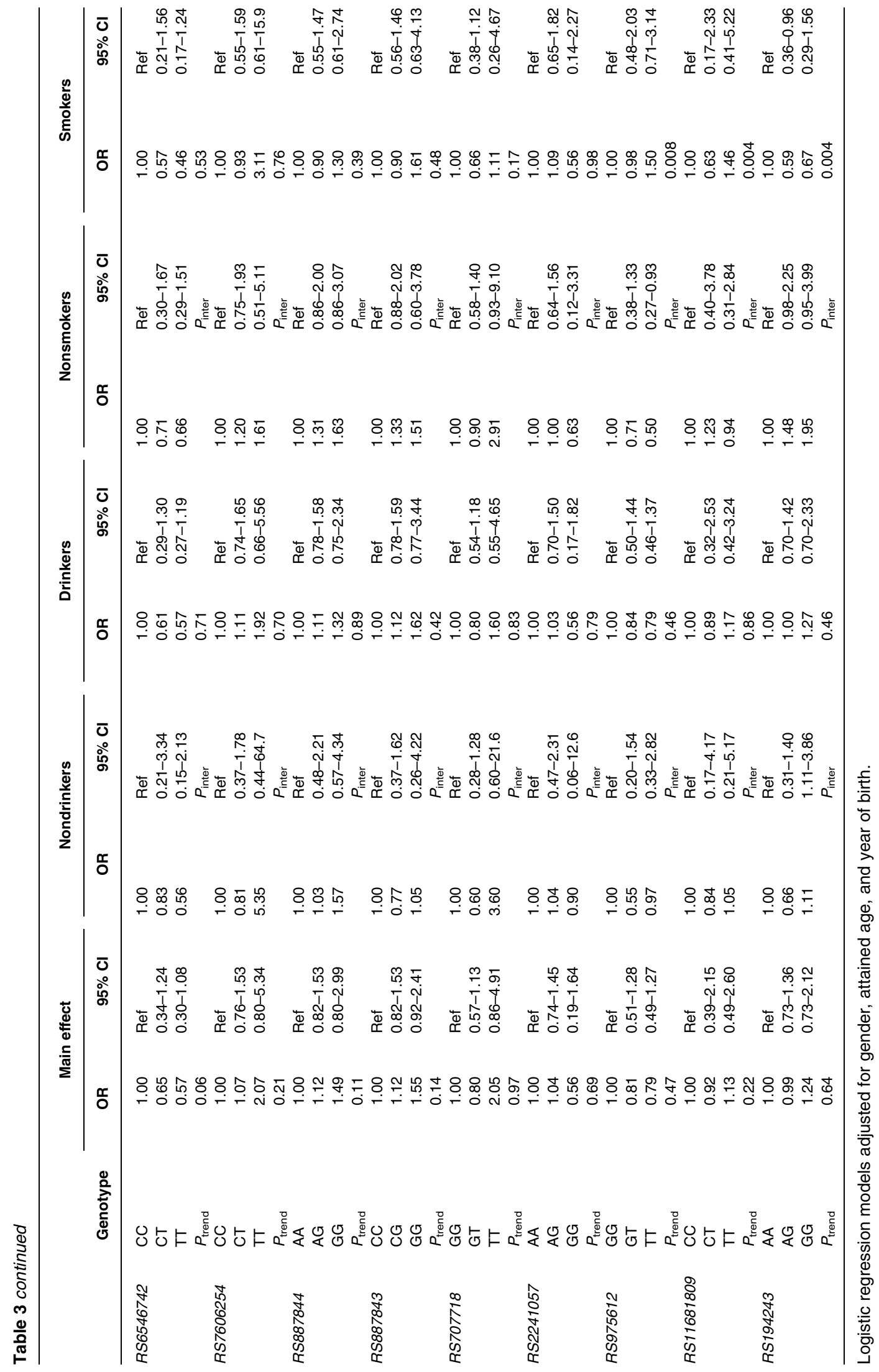


trend for the SNP rs223554 in DIOI $\left(P_{\text {trend }}=0.07\right)$ and no association for the $D I O$ gene/region as a whole.

The importance of evaluating joint effects of metabolic polymorphisms and environmental exposures is underscored by the well-established interaction between NAT1 and NAT2 acetylation status and smoking for other cancer sites (Sanderson et al. 2007, Hein et al. 2009). We found significant interactions between $U G T 2 B 7, N A T 1$ polymorphisms and alcohol intake, and $C Y P 26 B 1$ polymorphisms, and smoking. As interactions were exposure specific, it seems unlikely that they were due to correlation between alcohol and smoking intake. Moreover, additional adjustment for smoking use while analyzing interaction with alcohol use and vice versa had no meaningful effect on the observed joint effects. As expected, the interaction findings at SNP level were consistent with these at the gene level. While analyses at the individual SNP level might provide useful insights on underlying mechanism behind interactions, these are challenging to interpret because we relied on tagging SNPs chosen to assure high coverage of the region under investigation irrespective of their phenotypic effects. In fact, all the SNPs for which we found significant interaction with smoking or alcohol use were intronic and their functional relevance remains unknown. On the other hand, interaction analyses at the gene level, while less revealing, take into account the LD structure among the SNPs via the permutation procedure we used and suggest potential importance for the region as a whole.

Several issues merit further consideration. Our study had high participation rates minimizing potential for selection bias. Because survival rates for PTC are exceptionally high, survival bias is unlikely. To minimize concerns about population stratification, all analyses were limited to individuals of European ancestry. Moreover, cases from the two studies were similar with regard to age at diagnosis, smoking status, tumor size, and allele frequencies. Other strengths of our study include thorough gene selection and dense gene coverage for genes related to a variety of detoxification pathways. Because thyroid cancer is a rare disease, most genetic studies of thyroid cancer are limited by sample size. By comparison, our study is relatively large with 344 cases. Nevertheless, our study had limited power to detect weak associations especially for less common genetic variants and interactions with alcohol and cigarette smoking. Another limitation is the use of tagging SNPs that are themselves unlikely to be the disease-related SNPs but are assumed to be in LD with the causal variant. To address these limitations, we excluded SNPs with MAF
$<10 \%$ and relied on robust gene/pathway ARTP methods combining SNP-specific $P$ values of trend to confirm main associations with risk of PTC and interactions. While we used data on alcohol and smoking intake to explore interactions with genetic polymorphisms, these were categorized into ever/never categories and we were unable to conduct more powerful dose-response analyses for heavy drinkers/ smokers compared to light drinkers/smokers. Although we acknowledge that the use of a smoking measure that incorporates intensity may be more informative, the data were sparse and it was difficult to evaluate smoking intensity by genotype in a meaningful way. We applied conservative multiple comparison corrections, but we cannot exclude the possibility of false positive (or false negative) findings. Additional studies with increased power and improved exposure assessment including GWAS are warranted to confirm and substantiate our findings.

In summary, our results suggest an interaction between genetic polymorphisms in several detoxification enzymes and alcohol and tobacco intake on risk of PTC. Additional studies with detailed information on substance intake and increased power to evaluate gene-environment interactions should be pursued to clarify the complex relationship between genes, environment, and thyroid cancer risk.

\section{Supplementary data}

This is linked to the online version of the paper at http://dx. doi.org/10.1530/ERC-11-0372.

\section{Declaration of interest}

The authors declare that there is no conflict of interest that could be perceived as prejudicing the impartiality of the research reported.

\section{Funding}

This work was supported in part by an American Thyroid Association Thyroid Cancer grant (principal investigator, Dr Sturgis), a National Institutes of Health U01 grant (grant number DE019765-01) (postdoctoral fellow, Dr Xu; principal investigator, Dr Adel El-Naggar), and Cancer Center Support Grant (grant number CA-16672) to The University of Texas M.D. Anderson Cancer Center (principal investigator, Dr John Mendelsohn). Dr Xu is currently a Cancer Prevention Postdoctoral Fellow at The University of Texas M.D. Anderson Cancer Center supported by Halliburton Employees Fellow in Cancer Prevention funds. This project has been funded in whole or in part with federal funds from the National Cancer Institute, National Institutes of Health, under contract number HHSN261200800001E. The content of this 
publication does not necessarily reflect the views or policies of the Department of Health and Human Services, nor does mention of trade names, commercial products, or organizations imply endorsement by the US Government.

\section{Acknowledgements}

We are deeply indebted to the late Dr Elaine Ron, whose contribution to this work was of great significance. This research was supported in part by the Intramural Research Program of the Division of Cancer Epidemiology and Genetics, National Cancer Institute, National Institutes of Health. We are grateful to the radiologic technologists who participated in the U.S. Radiologic Technologists Study; Jerry Reid of the American Registry of Radiologic Technologists for continued support of this study; Diane Kampa and Allison Iwan of the University of Minnesota for data collection and study coordination; Liliana Mugartegui for patient recruitment, data collection, and study coordination at the University of Texas M.D. Anderson Cancer Center; and Laura Bowen of Information Management Systems for biomedical computing statistical support.

\section{References}

Barter RA \& Klaassen CD 1994 Reduction of TH levels and alteration of thyroid function by four representative UDPglucuronosyltransferase inducers in rats. Toxicology and Applied Pharmacology 128 9-17. (doi:10.1006/taap. 1994.1174)

Benjamini Y \& Hochberg Y 1995 Controlling the false discovery rate: a practical and powerful approach to multiple testing. Journal of the Royal Statistical Society 57 289-300.

Carlson CS, Eberle MA, Rieder MJ \& Yi Q 2004 Selecting a maximally informative set of single-nucleotide polymorphisms for association analyses using linkage disequilibrium. American Journal of Human Genetics 74 106-120. (doi:10.1086/381000)

De Felice M \& Di Lauro R 2004 Thyroid development and its disorders: genetics and molecular mechanisms. Endocrine Reviews 25 722-746. (doi:10.1210/er.2003-0028)

Gudmundsson J, Sulem P, Gudbjartsson DF, Jonasson JG, Sigurdsson A, Bergthorsson JT, He H, Blondal T, Geller F, Jakobsdottir M et al. 2009 Common variants on 9q22.33 and $14 q 13.3$ predispose to thyroid cancer in European populations. Nature Genetics 41 460-464. (doi:10.1038/ng.339)

Gudmundsson J, Sulem P, Gudbjartsson DF, Jonasson JG, Masson G, He H, Jonasdottir A, Sigurdsson A, Stacey SN, Johannsdottir H et al. 2012 Discovery of common variants associated with low TSH levels and thyroid cancer risk. Nature Genetics 44 319-322. (doi: 10.1038/ng.1046)

Guignard R, Truong T, Rougier Y, Baron-Dubourdieu D \& Guénel P 2007 Alcohol drinking, tobacco smoking, and anthropometric characteristics as risk factors for thyroid cancer: a countrywide case-control study in New Caledonia. American Journal of Epidemiology

166 1140-1149. (doi:10.1093/aje/kwm204)

Guilhen AC, Bufalo NE, Morari EC, Leite JL, Assumpcao LV, Tincani AJ \& Ward LS 2009 Role of the

$\mathrm{N}$-acetyltransferase 2 detoxification system in thyroid cancer susceptibility. Clinical Cancer Research $\mathbf{1 5}$ 406-412. (doi:10.1158/1078-0432.CCR-08-1835)

Hein DW, Doll MA, Fretland AJ, Leff MA, Webb SJ, Xiao GH, Devanaboyina US, Nangju NA \& Feng Y 2009 Molecular genetics and epidemiology of the NAT1 and NAT2 acetylation polymorphisms. Cancer Epidemiology, Biomarkers \& Prevention $929-42$.

Hernández A, Xamena N, Surrallés J, Galofré P, Velázquez A, Creus A \& Marcos R 2008 Role of GST and NAT2 polymorphisms in thyroid cancer. Journal of Endocrinological Investigation 31 1025-1031.

Ho T, Li G, Lu J, Zhao C, Wei Q \& Sturgis EM 2009 Association of XRCC1 polymorphisms and risk of differentiated thyroid carcinoma: a case-control analysis. Thyroid 19 129-135. (doi:10.1089/thy.2008.0153)

Hood A, Hashmi R \& Klaassen CD 1999 Effects of microsomal enzyme inducers on thyroid-follicular cell proliferation, hyperplasia, and hypertrophy. Toxicology and Applied Pharmacology 160 163-170. (doi:10.1006/ taap.1999.8752)

Howlader N, Noone AM, Krapcho M, Neyman N, Aminou R, Waldron W, Altekruse SF, Kosary CL, Ruhl J, Tatalovich Z et al. 2011 SEER Cancer Statistics Review, 1975-2008, National Cancer Institute. Bethesda, MD, http://seer. cancer.gov/csr/1975_2008/, based on November 2010 SEER data submission, posted to the SEER web site, 2011.

Klaassen CD \& Hood AM 2001 Effects of microsomal enzyme inducers on thyroid follicular cell proliferation and TH metabolism. Toxicologic Pathology 29 34-40. (doi:10.1080/019262301301418838)

Landa I \& Robledo M 2011 Association studies in thyroid cancer susceptibility: are we on the right track? Journal of Molecular Endocrinology 47 R43-R58. (doi:10.1530/ JME-11-0005)

Lemos MC, Carrilho F, Rodrigues F, Coutinho E, Gomes L, Carvalheiro M \& Regateiro FJ 2007 Genetic polymorphism of CYP2D6 influences susceptibility to papillary thyroid cancer. Clinical Endocrinology 67 180-183. (doi:10.1111/j.1365-2265.2007.02858.x)

Lemos MC, Coutinho E, Gomes L, Carrilho F, Rodrigues F, Regateiro FJ \& Carvalheiro M 2008 Combined GSTM1 and GSTT1 null genotypes are associated with a lower risk of papillary thyroid cancer. Journal of Endocrinological Investigation 31 542-545.

Liu J, Liu Y, Barter RA \& Klaassen CD 1995 Alteration of thyroid homeostasis by UDP-glucuronosyltransferase inducers in rats: a dose-response study. Journal of Pharmacological and Experimental Therapeutics 273 977-985.

Lönn S, Bhatti P, Alexander BH, Pineada MA, Doody MM, Struewing JP \& Sigurdson A 2007 Papillary thyroid 
cancer and polymorphic variants in TSHR- and RETrelated genes: a nested case-control study within a cohort of US radiologic technologists. Cancer Epidemiology, Biomarkers \& Prevention 16 174-177. (doi:10.1158/ 1055-9965.EPI-06-0665)

Mack WJ, Preston-Martin S, Dal Maso L, Galanti R, Xiang M, Franceschi S, Hallquist A, Jin F, Kolonel L, La Vecchia C et al. 2003 A pooled analysis of case-control studies of thyroid cancer: cigarette smoking and consumption of alcohol, coffee, and tea. Cancer Causes and Control 14 773-785. (doi:10.1023/ A:1026349702909)

Meinhold CL, Park Y, Stolzenberg-Solomon RZ, Hollenbeck AR, Schatzkin A \& Berrington de Gonzalez A 2009 Alcohol intake and risk of thyroid cancer in the NIH-AARP Diet and Health Study. British Journal of Cancer 101 1630-1634. (doi:10.1038/sj.bjc.6605337)

Meinhold CL, Ron E, Schonfeld SJ, Alexander BH, Freedman DM, Linet MS \& Berrington de González A 2010 Nonradiation risk factors for thyroid cancer in the US Radiologic Technologists Study. American Journal of Epidemiology 171 242-252. (doi:10.1093/aje/kwp354)

Panicker V, Cluett C, Shields B, Murray A, Parnell KS, Perry JR, Weedon MN, Singleton A, Hernandez D, Evans $\mathrm{J}$ et al. 2008 A common variation in deiodinase 1 gene DIO1 is associated with the relative levels of free thyroxine and triiodothyronine. Journal of Clinical Endocrinology and Metabolism 93 3075-3081. (doi:10. 1210/jc.2008-0397)

Rossing MA, Cushing KL \& Voigt LF 2000 Risk of papillary thyroid cancer in women in relation to smoking and alcohol consumption. Epidemiology 11 49-54. (doi:10. 1097/00001648-200001000-00011)

Sanderson S, Salanti G \& Higgins J 2007 Joint effects of the $N$-acetyltransferase 1 and 2 (NAT1 and NAT2) genes and smoking on bladder carcinogenesis: a literature-based systematic HuGE review and evidence synthesis. American Journal of Epidemiology 166 741-751. (doi:10. 1093/aje/kwm167)

Sigurdson AJ, Doody MM, Rao RS, Freedman DM, Alexander BH, Hauptmann M, Mohan AK, Yoshinaga S, Hill DA \& Tarone R 2003 Cancer incidence in the US radiologic technologists health study, 1983-1998. Cancer 97 3080-3089. (doi:10.1002/cncr.11444)

Siraj AK, Ibrahim M, Al-Rasheed M, Abubaker J, Bu R, Siddiqui SU, Al-Dayel F, Al-Sanea O, Al-Nuaim A, Uddin S et al. 2008 Polymorphisms of selected xenobiotic genes contribute to the development of papillary thyroid cancer susceptibility in Middle Eastern population. BMC Medical Genetics 9 61. (doi:10.1186/1471-2350-9-61)

Takahashi M, Saenko VA, Rogounovitch TI, Kawaguchi T, Drozd VM, Takigawa-Imamura H, Akulevich NM, Ratanajaraya C, Mitsutake N, Takamura N et al. 2010 The FOXE1 locus is a major genetic determinant for radiation-related thyroid carcinoma in Chernobyl. Human Molecular Genetics 19 2516-2523. (doi:10.1093/ $\mathrm{hmg} / \mathrm{ddq} 123$ )

Tarone RE 1990 A modified Bonferroni method for discrete data. Biometrics 46 515-522. (doi:10.2307/2531456)

Yu K, Li Q, Bergen AW, Pfeiffer RM, Rosenberg PS, Caporaso N, Kraft P \& Chatterjee N 2009 Pathway analysis by adaptive combination of P-values. Genetic Epidemiology 33 700-709. (doi:10.1002/gepi.20422)

\author{
Received in final form 14 February 2012 \\ Accepted 2 March 2012 \\ Made available online as an Accepted Preprint \\ 2 March 2012
}

